NOTA TÉCNICA:

\title{
OPERACIONALIZAÇÃO DE UMA PLANTA DE PIRÓLISE RÁPIDA DE BIOMASSA COM REATOR DE LEITO FLUIDIZADO
}

Rodrigo Aparecido Jordan ${ }^{1}$, Luis Augusto Barbosa Cortez ${ }^{2}$, Juan Miguel Mesa Perez ${ }^{3}$, Henry R. Mari Mesa ${ }^{4}$, José Dilcio Rocha ${ }^{5}$

\section{RESUMO}

Neste trabalho são discutidos os principais problemas encontrados durante a operação da planta piloto de pirólise rápida de biomassa, pertencente à Universidade Estadual de Campinas- Unicamp, Brasil. Essa planta foi ajustada para a produção de bio-óleo, a partir de resíduos de biomassa de pequeno tamanho. Durante os testes, os principais problemas identificados foram: escoamento de vapores da pirólise pelo sistema de alimentação de biomassa; travamento da rosca de alimentação de biomassa; segregação da biomassa no leito; sinterização do material inerte; acúmulo de biomassa e de carvão vegetal dentro do reator; dificuldade para o aquecimento do inerte e baixa eficiência de recuperação de bio-óleo. Os resultados dos testes exploratórios permitiram definir condições operacionais para possibilitar o trabalho estável do reator, aumentar o conhecimento sobre os fenômenos que ocorrem durante a pirólise rápida em leito fluidizado, além do estabelecimento de faixas operacionais para vários fatores independentes, visando a futuros trabalhos de otimização experimental.

Palavras-chave: resíduos de biomassa, bioenergia, bio-óleo, carvão vegetal,aquecimento, segregação

\section{OPERATIONALIZATION OF A FAST PYROLYSIS PLANT OF BIOMASS WITH FLUIDIZED BED REACTOR}

\begin{abstract}
We discuss the main problems encountered during the operation of the fast pyrolysis plant pilot of biomass belonging to the State University of Campinas, Unicamp-Brazil. This plant has been set for the production of bio-oil from waste biomass of small size. During testing, the main problems identified were: steam flow by the pyrolysis of biomass power, locking the thread supply of biomass, segregation of biomass in the bed, sintering of inert material, accumulation of biomass and charcoal inside the reactor, difficult to heat the inert and low efficiency of recovery of bio-oil. The results of exploratory tests allowed to set operating conditions to enable the stable work of the reactor, increasing knowledge about the phenomena that occur during fast pyrolysis fluidized bed, including the establishment of operating ranges for various independent factors in order to optimize future experimental work.
\end{abstract}

Keywords: waste biomass, bioenergy, bio-oil, charcoal, heating, segregation

Recebido para publicação em 06/10/2009. Aprovado em 27/04/2010

1- Prof. Doutor da FCA/UFGD. Pesquisador Colaborador da FEAGRI/UNICAMP.

2- Prof. Doutor da Faculdade de Engenharia Agrícola, UNICAMP, Campinas-SP. E-mail: cortez@reitoria.unicamp.br

3- Doutor em Engenharia Agrícola, Diretor Técnico da Empresa Bioware Tecnologia, Campinas-SP

4- Mestre em Engenharia Elétrica, Técnico da Empresa Bioware Tecnologia, Campinas-SP

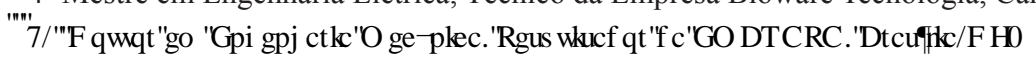




\section{INTRODUÇÃO}

O uso de biomassa para fins energéticos apresenta uma série de vantagens ambientais e econômicas, importantes no cenário atual. Por ser uma fonte renovável, além de economizar as fontes não renováveis, consegue fechar o ciclo do carbono, reduzindo a sua emissão para a atmosfera. Possibilita a criação de novos empregos, apresentando um menor investimento por posto de trabalho, quando comparado com o setor de combustíveis fósseis. Além disso, descentraliza regionalmente a produção.

Analisando as tecnologias das fontes energéticas alternativas renováveis, já suficientemente maduras para serem empregadas comercialmente, somente a biomassa, utilizada em processos modernos com elevada eficiência tecnológica, possui a flexibilidade de suprir energéticos, tanto para a produção de energia elétrica, quanto para a produção de combustíveis líquidos (CORTEZ, 2008).

Dentre as tecnologias para a conversão de biomassa em energia, tem-se a pirólise rápida, que se caracteriza pela degradação térmica do combustível sólido, a qual pode ser realizada em ausência completa do agente oxidante ou em uma quantidade tal que a gaseificação não ocorra extensivamente (OLIVARES GÓMEZ, 2008).

A pirólise rápida de biomassa para a produção otimizada da fração líquida aquosa orgânica (bio-óleo) é um processo de conversão termoquímica, ou seja, ocorre em temperaturas elevadas e envolve reações químicas. A tecnologia de leito fluidizado é interessante pela versatilidade da técnica, por sua relativa simplicidade, quando comparada com as demais opções (como a pirólise a vácuo, o cone rotativo, o vórtex ablativo, etc.) e pelos custos atrativos de implantação (BRIDGWATER, 2001). O bio-óleo obtido pela pirólise de biomassa pode ser usado como combustível renovável, em substituição ao diesel e ao óleo combustível, na geração estacionária de energia em sistemas termelétricos.

Atualmente, no Brasil, a pirólise rápida para produção de bio-óleo, dentre as tecnologias que estão sendo propostas para o aproveitamento energético da biomassa oriunda de resíduos gerados pela atividade agrícola, é a que se encontra num estágio mais avançado para uma aplicação a curto e médio prazo. Ainda assim, a operacionalização de plantas para operação contínua e, em escalas maiores, ainda requer a solução de problemas operacionais, como sistemas de alimentação de biomassa, reator e sistema de recuperação do bio-óleo.

A planta piloto de pirólise rápida de biomassa com o reator de leito fluidizado, desenvolvido pelos pesquisadores da Unicamp, o primeiro no Brasil para produção de bio-óleo, foi montada em 1998, nas instalações do Centro de Tecnologia Canavieira (CTC), antiga Copersucar, localizado na cidade de PiracicabaSP. A planta piloto foi batizada de PPR-200, fazendo alusão ao nome (Planta de Pirólise Rápida) e a sua capacidade (200 kg/h de biomassa seca).

São apresentados, neste trabalho, os problemas de funcionamento observados durante o início de operação desta planta piloto. São definidas as possíveis causas e propostas algumas soluções, as quais, aplicadas, mostraram resultados satisfatórios. As análises operacionais realizadas contribuíram para aumentar o conhecimento dos fenômenos que ocorrem durante a pirólise rápida em leito fluidizado, objetivando a determinação de parâmetros de projeto e o aumento de escala dos equipamentos.

\section{MATERIAIS E MÉTODOS}

Os testes exploratórios, visando à operação estável do reator, foram realizados na planta piloto de pirólise rápida da Unicamp (Figura 1). A instalação experimental em escala piloto está baseada na tecnologia de leito fluidizado e utiliza ar como agente de fluidização.

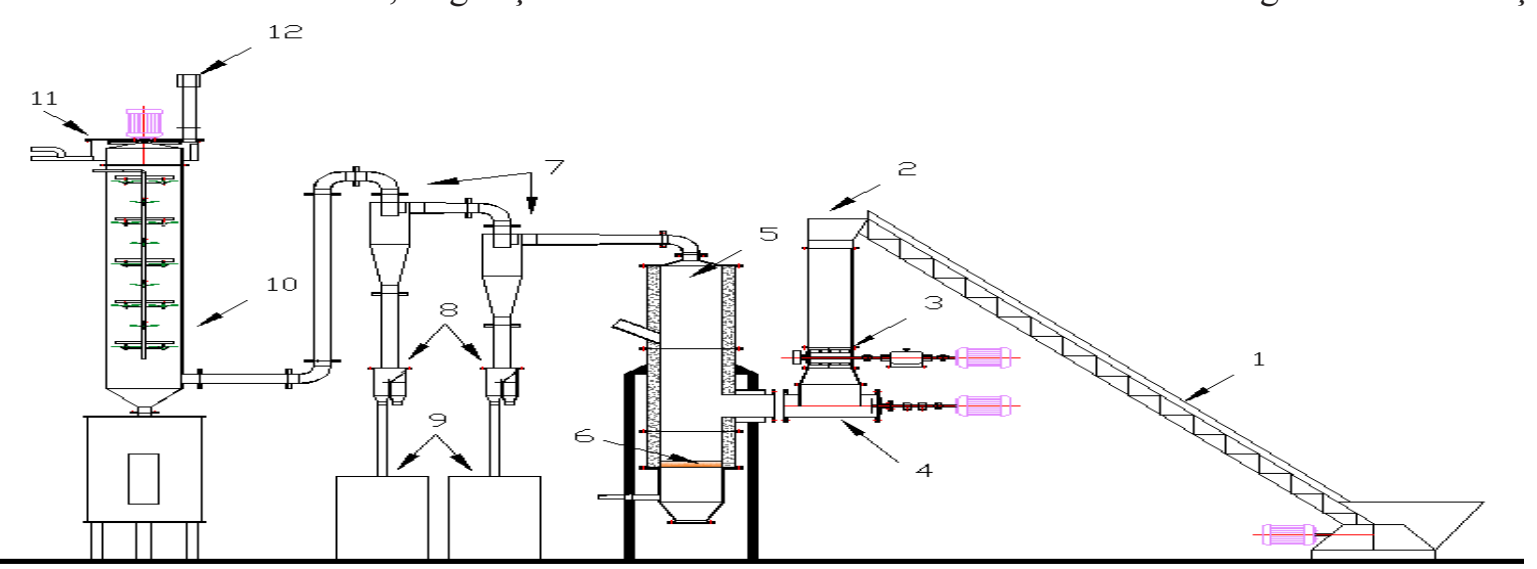

Figura 1. Esquema da planta de pirólise rápida da Unicamp. 
Conforme indicado na Figura 1, as principais partes que compõem a planta são: sistema de alimentação de biomassa composto por: esteira transportadora (1), silo (2), dosador de biomassa (3) e rosca alimentadora (4); reator de leito fluidizado (5) com placa distribuidora de ar (6); dois ciclones em série para separar os finos de carvão (7); válvula para amostragem de carvão (8) com tambores para armazenar o carvão (9); sistema de recuperação de finos de carvão via úmida (10); sistema de recuperação de bio-óleo (11); e, chaminé (12).

$\mathrm{O}$ reator é cilíndrico e foi construído em aço carbono com diâmetro interno de $417 \mathrm{~mm}$, revestido internamente com isolamento térmico refratário. Sua capacidade nominal de alimentação é de 200 kg.h-1 de biomassa polidispersa seca e utiliza um leito de material inerte durante a sua operação. Um sistema de aquisição de dados registra e armazena valores de temperatura e pressão estática ao longo da altura do reator e na saída dos sistemas de recuperação.

No início da operação, o reator é aquecido utilizando-se finos de carvão vegetal oriundos do processo de carbonização da lenha de eucalipto, processo que continua até que o leito de areia sílica atinja uma temperatura média entre $550 \mathrm{oC}$ e $600 \mathrm{oC}$. Nessas condições, e encontrando-se a vazão mássica de ar no valor estabelecido, inicia-se a alimentação com biomassa, não sendo mais necessário a adição de carvão vegetal. Uma vez que parte da biomassa (cerca de 10 a 15\%) é consumida para fornecer calor ao processo. Os produtos da pirólise tais como carvão, bio-óleo e água ácida são produzidos continuamente e armazenados em reservatórios adequados.

A biomassa utilizada nos testes foi capimelefante, da variedade Pennisetum purpureum com distribuição de tamanho de partículas entre 1,68 e $2,38 \mathrm{~mm}$.

O material inerte utilizado é areia sílica (dióxido de silício $=\mathrm{SiO}_{2}$ ) com partículas de $0,164 \mathrm{~mm}$ de diâmetro médio e 0,6 de esfericidade média. A velocidade mínima de fluidização registrada a $25{ }^{\circ} \mathrm{C}$ é de $0,025 \mathrm{~m} / \mathrm{s}$.

Durante os testes, foram acumulados mais de 200 horas de operação, sendo que cada teste teve uma duração média de 4 horas. Após a observação dos problemas e identificação das causas, a planta foi modificada tomando como base as soluções propostas. Novos testes foram realizados depois de implementadas as mudanças, sendo constatada sua efetividade.

\section{RESULTADOS E DISCUSSÕES}

A seguir são mostrados os principais problemas ocorridos e algumas das soluções propostas.

\section{Vazamento de gases da pirólise}

$\mathrm{Na}$ Figura 2, apresentam-se as características visuais do vazamento de gases da pirólise pelo sistema de alimentação. Quando isso acontece, os perfis de temperatura e pressão ao longo da altura do reator são instáveis (Figuras 3 e 4), prejudicando o processo. Quando não há vazamento de gases do reator pelo sistema de alimentação de biomassa, as características dos perfis de temperatura e pressão ao longo da altura do reator (Figuras 5 e 6) são mais estáveis.

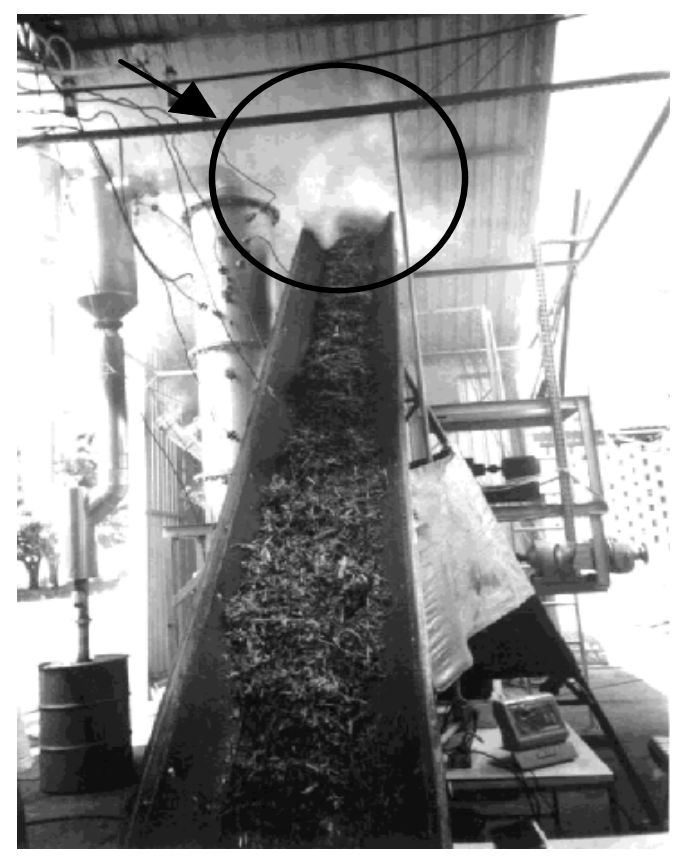

Figura 2. Vazamento de gases do reator de pirólise pelo sistema de alimentação de biomassa.

Das soluções testadas visando à diminuição do vazamento de gases, o aumento da percentagem de enchimento da rosca com biomassa mostrou-se bastante eficiente. O duto no qual está situada a rosca sem fim é um caminho preferencial para o escoamento dos gases da pirólise. O vazamento destes gases pelo sistema de alimentação torna inviável a operação do reator e do sistema de alimentação. Assim, o aumento da percentagem de enchimento da rosca, dificulta a passagem dos gases. Isto pode ser alcançado através da regulagem da velocidade do dosador e da rosca sem fim. 


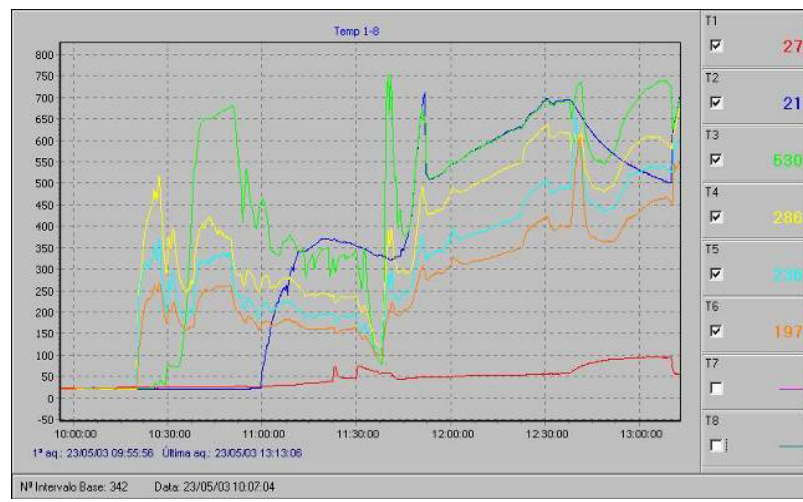

Figura 3. Perfis de temperatura no reator com o vazamento de gases da pirólise através do sistema de alimentação de biomassa.

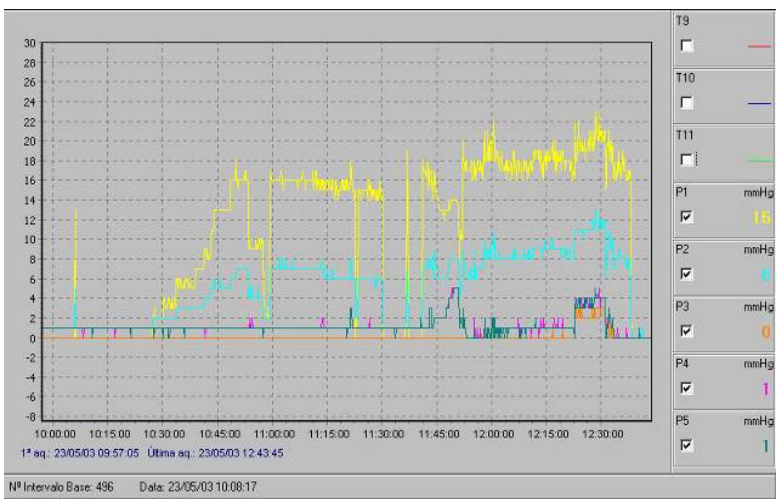

Figura 4. Perfis de pressão no reator com o vazamento de gases da pirólise através do sistema de alimentação de biomassa.

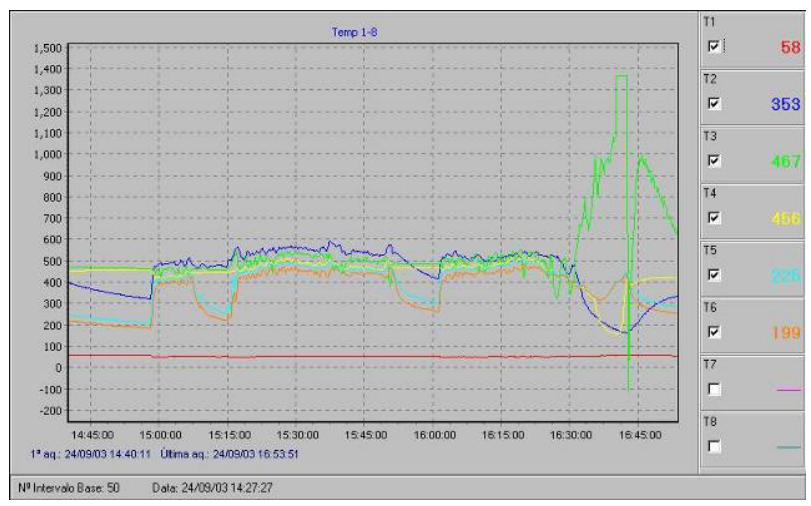

Figura 5.Perfis de temperatura no reator sem o vazamento de gases da pirólise através do sistema de alimentação de biomassa.

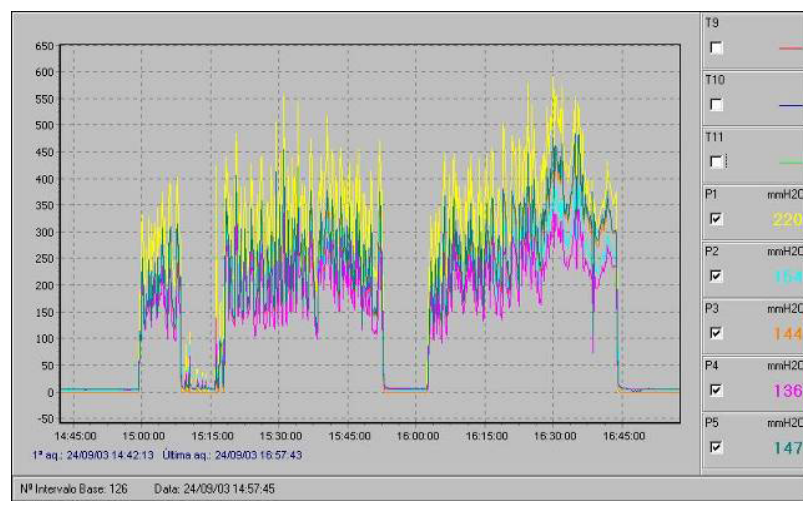

Figura 6. Perfis de pressão no reator sem o vazamento de gases da pirólise através do sistema de alimentação de biomassa

No Quadro 1, estão mostradas algumas condições de operação com diferentes ajustes de velocidade para o dosador e a rosca sem fim, objetivando obter uma maior percentagem de enchimento desta. Onde, não foi observado vazamento de gases para nenhuma destas condições. Estes resultados foram obtidos em experimentos a quente realizados com capim-elefante.

Pode-se verificar que para todas as condições testadas, a percentagem de enchimento da rosca situou-se numa faixa compreendida entre 33 e $40 \%$. A massa de biomassa necessária para obter $100 \%$ de enchimento da rosca $\left(0,073 \mathrm{~m}^{3}\right)$ é de $4,1 \mathrm{~kg}$.

Outra solução encontrada para eliminar o vazamento de gases pelo sistema de alimentação, foi a diminuição da área efetiva do duto da rosca sem fim, obtida com o aumento do diâmetro do eixo central (Figura 7a). Para manter a capacidade de alimentação da rosca pode ser incrementada a velocidade de rotação. Os testes de avaliação mostraram esta solução como sendo eficiente. Para efeito de comparação na Figura $7 \mathrm{~b}$ mostra-se a forma da rosca sem fim antes de ser modificada.

O aumento do diâmetro do eixo da rosca sem fim, apresenta a vantagem de manter a velocidade de alimentação ou, mesmo, aumentá-la. Sendo que o aumento da percentagem de enchimento pela redução da velocidade da rosca sem fim

Quadro 1. Condições de alimentação nas quais não se verificou vazamento de gases da pirólise

\begin{tabular}{ccccc}
\hline $\begin{array}{c}\text { Velocidade do } \\
\text { dosador (rpm) }\end{array}$ & $\begin{array}{c}\text { Velocidade da } \\
\text { rosca sem fim } \\
(\mathbf{r p m})\end{array}$ & $\begin{array}{c}\text { Fluxo de biomassa } \\
\text { descarregada ao } \\
\text { reator } \mathbf{( k g} / \mathbf{h})\end{array}$ & $\begin{array}{c}\text { Massa de } \\
\text { biomassa na rosca } \\
\mathbf{( k g )}\end{array}$ & $\begin{array}{c}\text { Taxa de } \\
\text { enchimento da } \\
\text { rosca } \mathbf{( \% )}\end{array}$ \\
\hline 2,29 & 7,4 & 70 & 1,37 & 33 \\
2,92 & 8,4 & 80 & 1,61 & 39 \\
4,1 & 10,74 & 120 & 1,68 & 40 \\
\hline
\end{tabular}




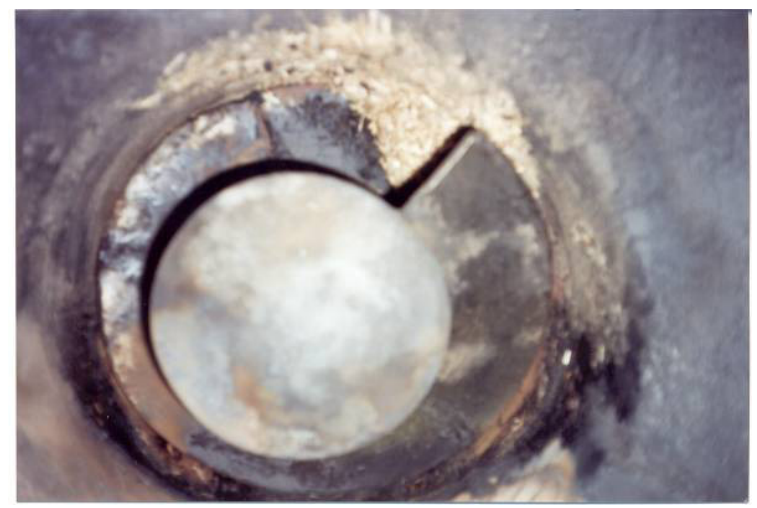

Figura 7a. Rosca sem fim com o diâmetro do eixo aumentado.

é possível até um determinado limite. Pois, quando a velocidade é muito reduzida, ocorre o aquecimento da biomassa ainda dentro da rosca, pela proximidade com o reator, por causa da alta temperatura do leito. Com isto, tem-se a formação de vapor d'água próximo a alimentação da rosca, na saída do dosador. Este vapor acaba se condensando nesta região, sendo depois arrastado para o interior do reator, causando problemas em sua operação .

Outro problema da velocidade reduzida de alimentação é a queima da biomassa ainda no interior da rosca sem fim, antes da entrada no reator. O uso de roscas com passo variável temse mostrado eficiente nos testes posteriores aos experimentos aqui apresentados. Menor passo no primeiro tramo de rosca garante enchimento total do duto. Sistemas de alimentação com diâmetro pequeno do duto e alta velocidade de giro da rosca garantem maior resistência ao escoamento dos gases e tempo de residência da biomassa na rosca pequena.

\section{Travamento da rosca de alimentação de biomassa}

O travamento da rosca aconteceu com maior frequência quando a alimentação foi realizada na fase densa do leito de inerte. Inicialmente, a biomassa acumulava-se no interior do leito e, em seguida, compactava-se na ponta da rosca sem fim (Figura 8), na entrada para o reator. A tentativa em se manter a alimentação nestas condições, poderia levar a ocorrência de danos, tanto na rosca sem fim, quanto no motor de acionamento desta.

Adotou-se como solução para amenizar o

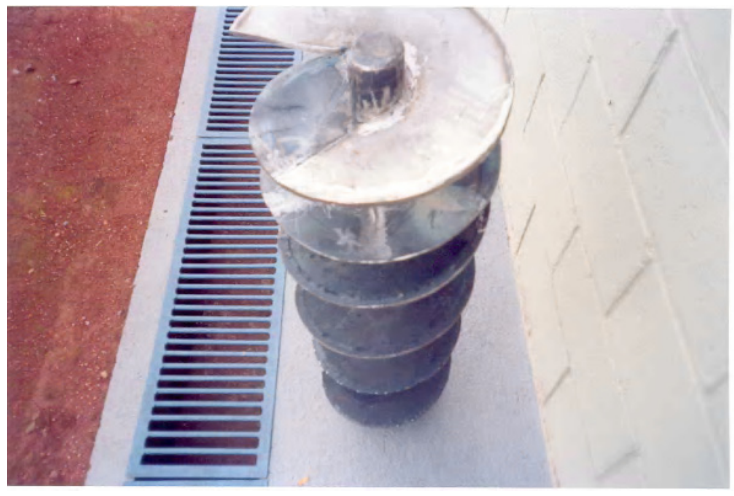

Figura 7b. Rosca sem fim antes da modificação.

problema, a alimentação da biomassa acima da fase densa do leito de inertes. A redução da densidade do leito também é uma opção para evitar que a rosca embuche com a biomassa.

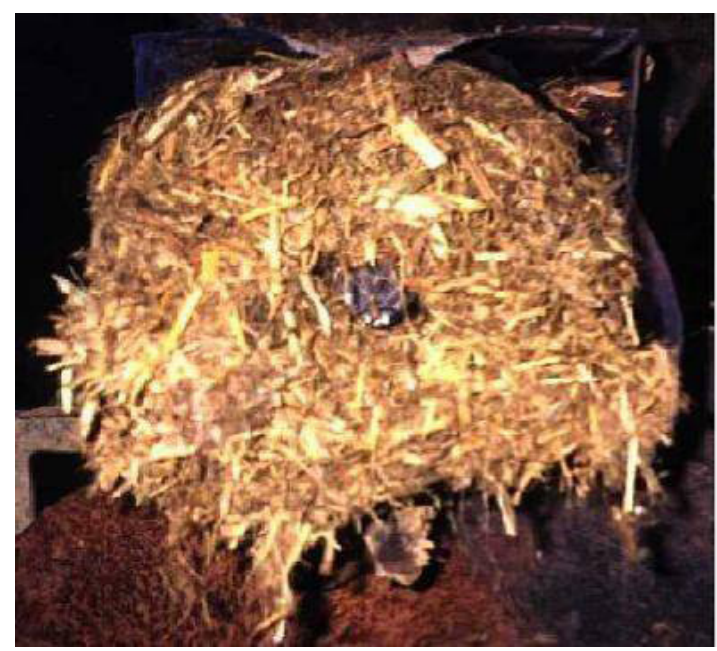

Figura 8. Aspecto da rosca sem fim quando da ocorrência de compactação, levando ao travamento.

\section{Sinterização do material inerte no leito}

A sinterização do material inerte (Figura 9) ocorre pela elevação da temperatura do leito acima do valor correspondente ao ponto de fusão do material, composto por uma mistura de areia e biomassa. A presença dos elementos potássio e sódio presentes nas cinzas da biomassa diminuem o ponto de fusão da mistura cinzas-material inerte. Outras impurezas presentes na biomassa, como pedras e terra, também contaminam o leito de inerte, dificultando a operação do reator. Pontos de alta temperatura acontecem quando a mistura entre a biomassa e o material inerte é inadequada, 




a)

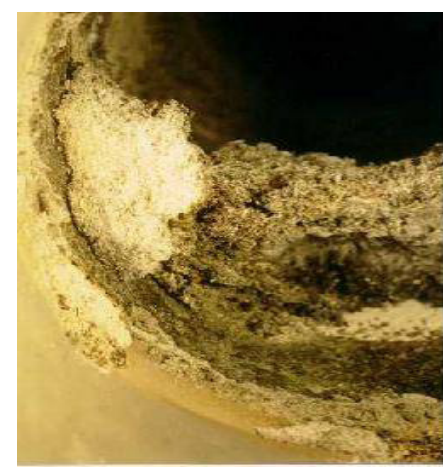

b)

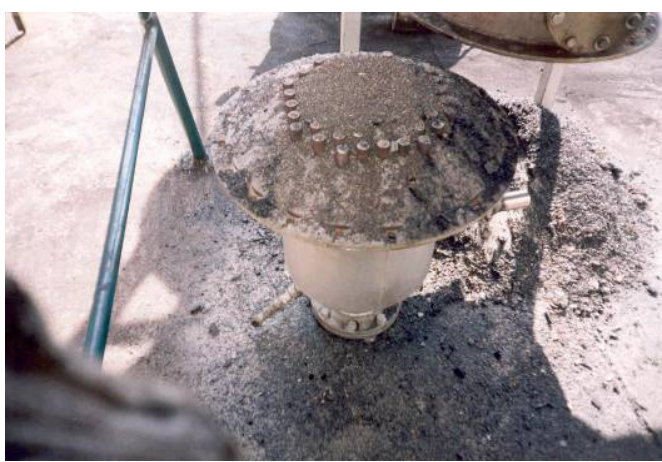

c)

Figura 9. Sinterização do material inerte: a) pedras no leito; b) paredes do reator; c) Pedras acumuladas no leito de inerte.

provocando a segregação da biomassa em zonas específicas dentro do leito de inerte.

\section{Segregação de biomassa no reator}

A biomassa pode segregar-se na parte inferior do leito ou em sua superfície. Em ambas as situações, a temperatura do leito aumenta rapidamente na região onde a camada de biomassa segrega-se, podendo, também, ocasionar a sinterização do material do leito. Se a velocidade superficial do gás é próxima à velocidade mínima de fluidização, a camada de biomassa forma-se na parte superior do leito. Para valores maiores de velocidade superficial do gás, acima da velocidade mínima de fluidização, acontece a inversão da camada, ou seja, a biomassa segrega-se na parte inferior do leito de inerte.

Esses fenômenos foram estudados por Rasul (2000), com misturas binárias de materiais inertes e bagaço de cana-de-açúcar. O estudo demonstrou que a inversão da camada acontece para valores de velocidade superficial do gás entre a velocidade de mínima fluidização $\left(u_{m f}\right)$ e a velocidade mínima de bolhas $\left(u_{m b}\right)$. Essa última foi definida para a máxima porosidade da fase densa do leito de inerte. A relação $u_{m b} \mu_{m f}$ é uma medida do grau de expansão do leito de inerte.

$\mathrm{Na}$ Figura 10, publicada por Rasul (1999), mostra os limites para a ocorrência de mistura ou segregação do leito fluidizado para o sistema binário composto por material inerte (areia) e bagaço de cana-de-açúcar. Onde, $\rho_{p} / \rho_{p}$ é a relação entre as densidades da biomassa e do material inerte e, $d_{p} / d_{p}$ é a relação entre os diâmetros das partículas de biomassa e do material inerte.

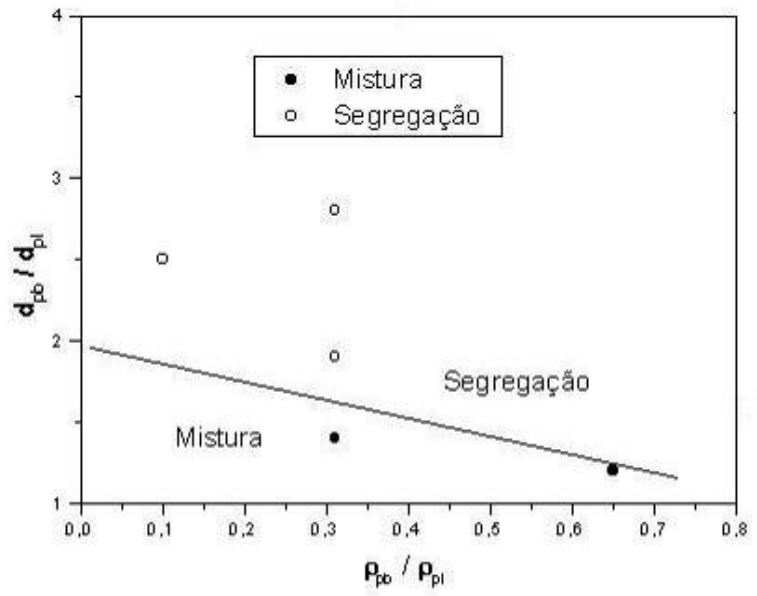

Figura 10. Limites para ocorrência de mistura ou segregação em leito fluidizado composto por mistura de areia e bagaço de cana-de-açúcar.

\section{Acúmulo de biomassa e carvão vegetal no leito}

Observou-se o acúmulo de biomassa durante algumas partidas do reator, obrigando a interrupção do início da operação para limpeza e nova partida. Pois, uma vez acumulada a biomassa no leito não se conseguia mais estabilizar o sistema na condição de operação. Constatou-se que o problema ocorria quando era feita a adição de biomassa com a temperatura do leito inferior a $400{ }^{\circ} \mathrm{C}$. Com a entrada de biomassa na condição ambiente, a temperatura era reduzida a um valor menor ainda, aumentando o tempo de residência, o que implicava no consequente acúmulo, impedindo que a temperatura de pirólise fosse atingida, estagnando a operação (Figura 11).

$\mathrm{O}$ aquecimento inicial do reator (partida) era realizado queimando-se GLP na superfície do leito de inerte, com a adição de pequenas quantidades de ar. Dessa forma, a transferência de calor acontecia 
desde a superfície do leito até a placa distribuidora. Quando a temperatura no leito atingia $600{ }^{\circ} \mathrm{C}$, o GLP era desligado. Em seguida, aumentava-se a vazão do agente de fluidização e alimentava-se a biomassa. Durante esse processo, a temperatura do leito diminuía rapidamente, dificultando a partida do reator.

Para contornar este problema durante a partida, o leito passou a ser aquecido com carvão vegetal até atingir uma temperatura de $600^{\circ} \mathrm{C}$, para somente depois começar a alimentação de biomassa. Após a adição de biomassa, a temperatura se estabiliza na condição desejada para a pirólise $\left(450-500^{\circ} \mathrm{C}\right)$.

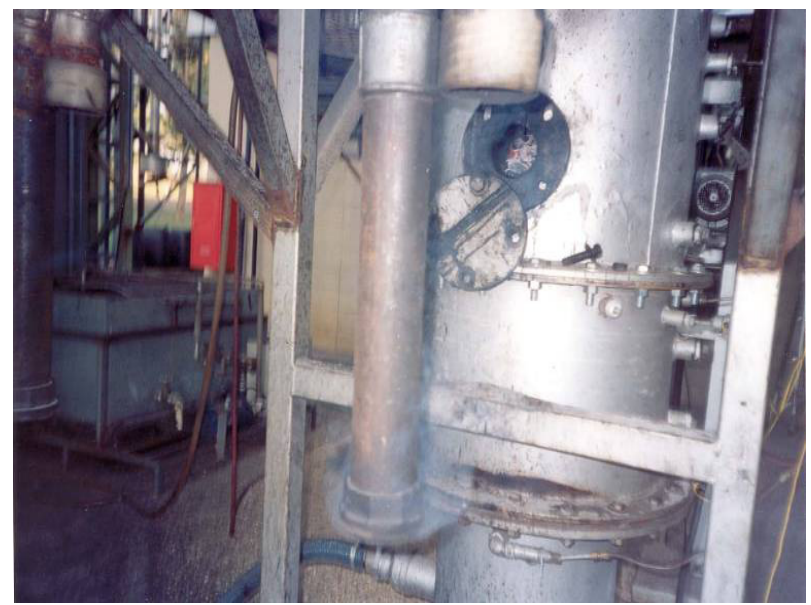

Figura 11. Acúmulo de biomassa e carvão no leito: estagnação do processo.

\section{Baixa eficiência de separação de bio-óleo}

Os primeiros testes resultavam em baixo rendimento de bio-óleo pelo fato de sua condensação em forma de névoa. Para isto, foi projetado um sistema de recuperação de bio-óleo que combina resfriamento dos gases por contato direto com os próprios líquidos da pirólise e posterior separação centrífuga. O projeto foi desenvolvido com base nos resultados obtidos utilizando um ventilador centrífugo, o qual é mostrado na Figura 12. As amostras de bio-óleo foram coletadas num recipiente de vidro colocado na parte inferior da carcaça do ventilador.

O sistema de separação desenvolvido é constituído basicamente por um cilindro de $0,5 \mathrm{~m}$ de diâmetro e $3 \mathrm{~m}$ de altura, ao longo do qual se distribuem bicos através dos quais se colocam em contato direto a fase gasosa e o ácido pirolenhoso. Um ventilador centrífugo de velocidade variável no topo do cilindro acelera as partículas de líquido contidas na fase gasosa até as paredes da carcaça do ventilador. A parede do cilindro está provida de defletores inclinados em sentido contrário ao do movimento dos gases. $\mathrm{O}$ ventilador opera em exaustão, reduzindo, dessa forma, as perdas de carga no sistema. A fração de bio-óleo, separada no ventilador centrífugo, é coletada independentemente da fração concentrada decorrente da recirculação do ácido pirolenhoso. (Figura 13).

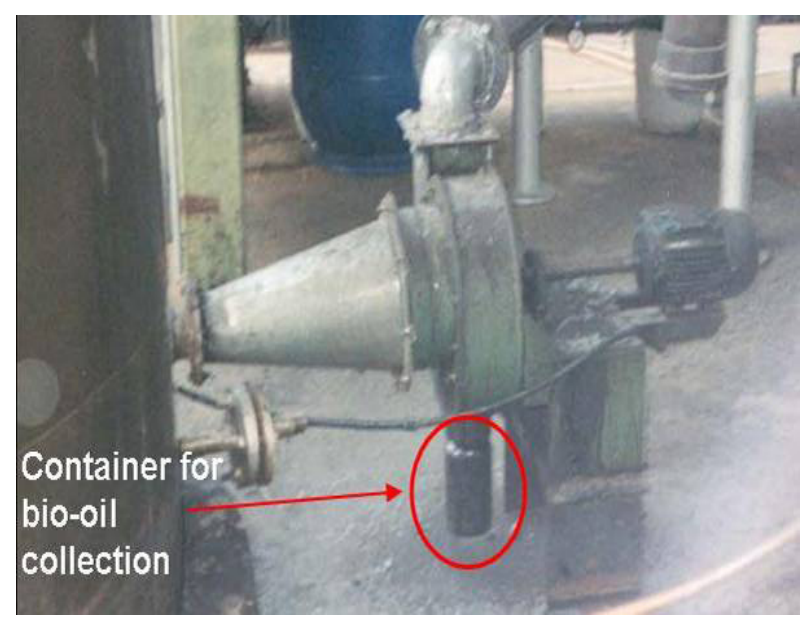

Figura 12. Ventilador centrífugo usado para a separação de amostras de bio-óleo.

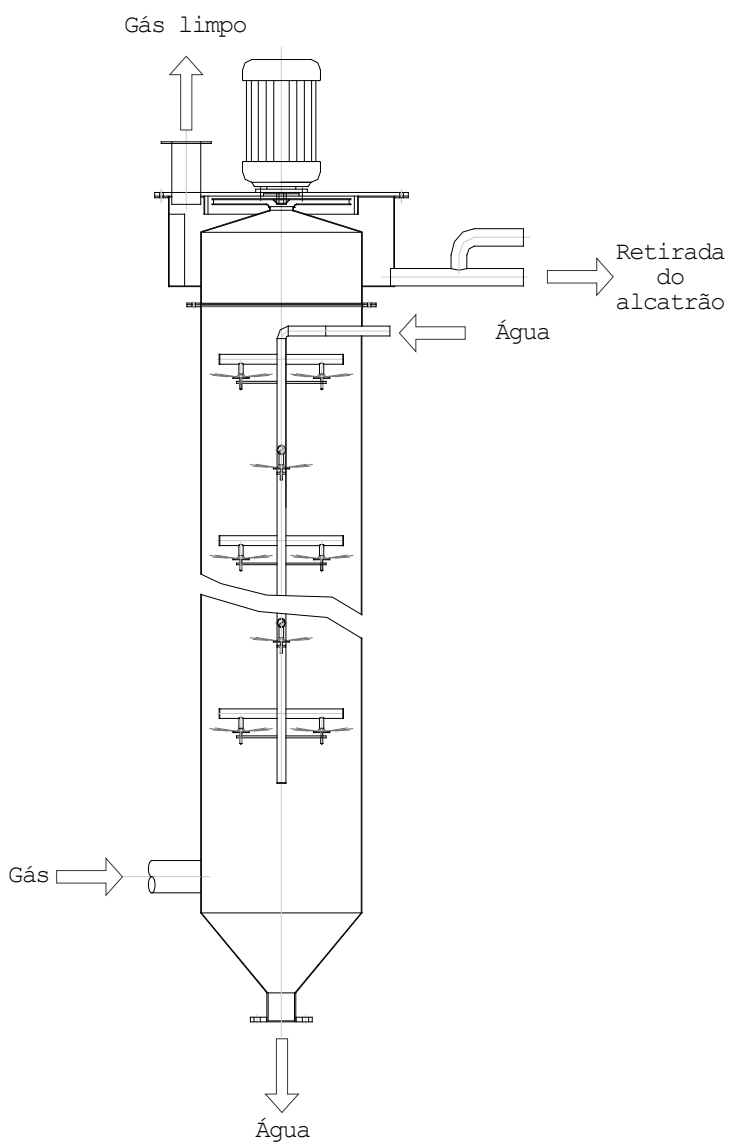

Figura 13. Sistema de recuperação de bio-óleo. 


\section{CONCLUSÕES}

- Os resultados dos testes exploratórios possibilitaram o trabalho estável da planta, maior conhecimento dos fenômenos que ocorrem durante a pirólise rápida em leito fluidizado, assim como o estabelecimento de níveis adequados para os fatores independentes identificados durante os trabalhos experimentais restantes.

- A diminuição da área efetiva da rosca sem fim para aumentar a percentagem de carregamento, como solução para redução do vazamento de gases da pirólise, mostrou-se mais efetiva do que a solução baseada na redução de velocidade da rosca e aumento da velocidade do dosador, pois, evita a operação do reator com excesso de biomassa, o que, além de provocar compactação, podendo ocasionar a ruptura do acoplamento do motor da rosca sem fim, ocasiona outros problemas relacionados com o aquecimento excessivo da biomassa dentro do sistema de alimentação.

- O problema de sinterização pode ser reduzido por meio de um tratamento adequado da biomassa a ser pirolisada, evitando que sejam levados para o interior do reator materiais como terra e pedras. O controle do processo para evitar que a temperatura se eleve para valores acima do ponto de fusão do material inerte do leito é importante, assim como reduzir a possibilidade de ocorrer segregação, também uma causa da sinterização, pois provoca o aumento da temperatura nas regiões onde a biomassa é segregada. A segregação pode ser evitada, utilizando relações adequadas entre os valores de diâmetro e massa específica da biomassa e do material inerte.

- O acúmulo de biomassa na partida do reator pode ser evitado com o aumento da temperatura inicial do leito fluidizado. Parte-se com uma temperatura um pouco maior do que a temperatura de pirólise. Temperaturas inferiores a $400{ }^{\circ} \mathrm{C}$ não são recomendadas para o início do processo. O controle de alimentação de biomassa é importante, para que a quantidade adicionada no início não seja muito grande.

- Para a operação satisfatória de uma planta de pirólise rápida, é fundamental possuir um bom sistema de alimentação de biomassa. Pois, vários problemas operacionais, verificados na planta piloto, tiveram relação com o sistema de alimentação. Por outro lado, o sistema de recuperação de bio-óleo possibilita o controle do tempo de residência dos vapores dentro do reator e nos equipamentos de separação, diminui a pressão estática no reator e evita vazamento de vapores pelo sistema de alimentação. Este sistema oferece a vantagem de obter separadamente o extrato ácido do bio-óleo.

\section{REFERÊNCIAS BIBLIOGRÁFICAS}

BRIDGWATER, A. V., Fast Pyrolysis of Biomass: A Handbook, Volume 2; CPL Press: Newbury, U.K., 2002; 432p.

BRIDGWATER, A.V. Towards the 'bio-refinery' fast pyrolysis of biomass. Renewable Energy World, JamesxJames Editores, Londres, vol. 4, No.1, JanFev 2001, p.66-83.

CORTEZ L. A. B., LORA E. E. S., CASTAÑEDA, J. A. Biomassa no Brasil e no mundo. In: CORTEZ, L. A. B.; LORA, E. E. S. e OLIVAREZ GÓMEZ, E. Biomassa para energia. Campinas: Editora da Unicamp, 2008. Cap.13, p.435 a 473.

OLIVAREZ GÓMES, E.; MESA PÉREZ, J. M.; BROSSARD, L. E. Pirólise rápida de materiais lignocelulósicos para a obtenção de bio-óleo. In: CORTEZ, L. A. B.; LORA, E. S. e OLIVAREZ GÓMEZ, E. Biomassa para energia. Campinas: Editora da Unicamp., 2008. Cap.11, p.353 a 418.

RASUL， M.G.; RUDOLPH，V. Fluidized bed combustion of Australian bagasse. Fuel, Netherlands, v.79, p.123-130, 2000. 